\title{
Socioeconomic Disparities and Air Pollution Exposure: a Global Review
}

\author{
Anjum Hajat $^{1} \cdot$ Charlene Hsia $^{2}$ • Marie S. O'Neill ${ }^{3}$
}

Published online: 18 September 2015

(C) Springer International Publishing AG 2015

\begin{abstract}
The existing reviews and meta-analyses addressing unequal exposure of environmental hazards on certain populations have focused on several environmental pollutants or on the siting of hazardous facilities. This review updates and contributes to the environmental inequality literature by focusing on ambient criteria air pollutants (including $\mathrm{NO}_{\mathrm{x}}$ ), by evaluating studies related to inequality by socioeconomic status (as opposed to race/ethnicity) and by providing a more global perspective. Overall, most North American studies have shown that areas where low-socioeconomic-status (SES) communities dwell experience higher concentrations of criteria air pollutants, while European research has been mixed. Research from Asia, Africa, and other parts of the world has shown a general trend similar to that of North America, but research in these parts of the world is limited.
\end{abstract}

This article is part of the Topical Collection on Air Pollution and Health

Anjum Hajat

Anjumh@uw.edu

Charlene Hsia

chsia12@uw.edu

Marie S. O’Neill

marieo@umich.edu

1 Department of Epidemiology, University of Washington, 4225 Roosevelt Way NE, Seattle, WA 98105, USA

2 Department of Environmental and Occupational Health Sciences, University of Washington, 4225 Roosevelt Way NE, Seattle, WA 98105, USA

3 Departments of Environmental Health Sciences and Epidemiology, University of Michigan, 6623 SPH Tower 1415 Washington Heights, Ann Arbor, MI 48109-2029, USA
Keywords Environmental justice $\cdot$ Environmental inequality $\cdot$ Criteria air pollutants $\cdot$ Air pollution . Socioeconomic status $\cdot$ Social disadvantage

\section{Introduction}

Several review articles related to inequalities in environmental hazards have been conducted over the years [1-9]. Existing reviews focus on a variety of important topics including the following: understanding the origins of environmental inequality [6], the policy implications of environmental justice (EJ) research [6], the interaction between the EJ advocacy movement and the research agenda [8], a methodological critique of the research [1], and finally the issue of whether environmental inequalities in the US disproportionately impact racial/ethnic minorities or populations of low socioeconomic status (SES) [7, 9]. The reviews of the existing body of research clearly highlight both the sheer volume of work around environmental inequalities and the complexity of the issues involved.

Although the terms EJ and environmental inequality are often used interchangeably in the literature, they do have distinct meanings. The concept of justice is normative, involving value judgments that can vary over place and time, while equality can be measured empirically and directly compared $[10 \bullet \bullet, 11]$. Inequalities can be defined across other domains such as process (equal access to the environmental decisionmaking process) and opportunity (equal opportunity to reduce or avoid exposures). These concepts, being difficult to measure, are not often found in empirical research (see Marshall [12••] and Clark [13] for papers that move beyond environmental inequality).

Beyond issues of fairness, environmental inequality research has important health implications. Several reviews 
focus on the relationship between environmental inequality and health $[2-4,14]$. The triple jeopardy hypothesis states that low-SES communities face (1) higher exposure to air pollutants and other environmental hazards and (2) increased susceptibility to poor health (primarily as a result of more psychosocial stressors, such as discrimination and chronic stress, fewer opportunities to choose health-promoting behaviors and poorer health status) resulting in (3) health disparities that are driven by environmental factors [15-17].

The purpose of this paper is to review empirical data in the environmental inequality literature from the past 10 years and to broaden the scope of previous reviews by including research from around the globe. We define environmental inequality as the distribution of air pollution across different socioeconomic groups and focus on papers that address this issue, rather than the process or opportunity domains. Our review focuses exclusively on one important environmental hazard, air pollution, and will only review research related to the distribution of air pollutants by SES. We recognize that some researchers will think that the exclusion of research on environmental inequalities by race/ethnicity is a limitation of this work. However, racial/ethnic composition of populations is highly diverse, worldwide, as is patterning of socioeconomic factors by race/ethnicity. Further, some countries do not routinely record race/ethnicity in health data. Additionally, interpretation and conceptualization of research on race/ ethnicity can be challenging [18]. Because of these factors and because we recognize that EJ is emerging as a critical issue in nations around the world, we decided to emphasize socioeconomic factors and not address race/ethnicity to allow for a more inclusive and generalizable global perspective.

Our focus on air pollution is further limited to the criteria air pollutants which are monitored and regulated by the US Environmental Protection Agency (EPA) and governmental agencies in other nations. Air quality standards for concentrations of particulate matter (PM, both particles $<2.5 \mu \mathrm{m}$ in aerodynamic diameter, $\mathrm{PM}_{2.5}$, and $<10 \mu \mathrm{m}$ in aerodynamic diameter, $\mathrm{PM}_{10}$ ), carbon monoxide $(\mathrm{CO})$, nitrogen dioxide $\left(\mathrm{NO}_{2}\right)$, ozone $\left(\mathrm{O}_{3}\right)$, sulfur dioxide $\left(\mathrm{SO}_{2}\right)$, and lead in outdoor air are set by the World Health Organization and individual governments around the world [19-21]. They are based on a review of the scientific evidence and are established to allow for an adequate margin of human health and safety, in light of the numerous health effects of criteria air pollutant exposure on human health [22-25].

\section{Methods}

A systematic review was conducted to identify all published studies on SES and ambient air pollution exposure. First, a literature search was performed using Science Direct, Web of Science, Google Scholar, and PubMed for the following keywords: "socioeconomic injustice and air pollution," "environmental justice and air pollution," "environmental inequity and air pollution," "socioeconomic status and air pollution," and "disparity and air pollution and environment." These keywords yielded a total of 440 published papers after removing duplicates across databases.

We excluded papers from this review if (1) they were published prior to 2005 , (2) they were mainly focused on quantifying the association between air pollution and a health outcome, with little attention to inequalities in exposure, (3) they did not conduct an empirical analysis (i.e., provided a framework or conceptual model), (4) they evaluated air pollutants other than the criteria air pollutants (e.g., hazardous air pollutants (HAPs), black carbon), (5) they used traffic-related metrics as a proxy for air pollution (e.g., distance to road, traffic density), (6) they combined several air pollutants (criteria and non-criteria) into an index without providing data on the individual ambient air pollutants themselves, and/or (7) they used only race/ethnicity classifications and not other socioeconomic factors to evaluate inequality. All papers were screened and reviewed by two study authors.

Ultimately, 37 studies met the inclusion criteria and were included in this review. Studies were organized by geographic location, with 22 North American studies, 10 European studies, and 5 studies from New Zealand, Asia, and Africa. Of these, some evaluated both criteria and non-criteria air pollutants and some evaluated both race/ethnicity and SES. Findings related to the non-criteria air pollutants and race/ethnicity are not described in the tables or text of this paper.

Given the differing methods used to assess the association between SES and air pollution, we did not attempt to quantify the overall magnitude of effect. Instead, we focused on describing the directionality of results to better understand if an overall trend emerges from the literature. We also discuss methodological issues, such as the analytic techniques employed to assess the association between SES and air pollution and the unit of analysis chosen by researchers. Furthermore, the different approaches used in air pollution exposure assessment and the types of SES metrics used are also discussed.

\section{Results}

The North American studies are outlined in Table 1. In general, these studies show a consistent finding: lower-SES individuals and communities are exposed to higher concentrations of criteria air pollutants. Comparison of magnitude of effects is difficult given differences across studies, but in those studies that used similar data sources and methods, we see relatively small increases in pollutant exposures associated with lower SES. For example, $\mathrm{PM}_{2.5}$ concentrations were $0.14,0.2$, 0.47 , and $0.9 \mu \mathrm{g} / \mathrm{m}^{3}$ higher in census tracts in North Carolina [26], in the northeast USA [27], in six US cities [28•], and in 


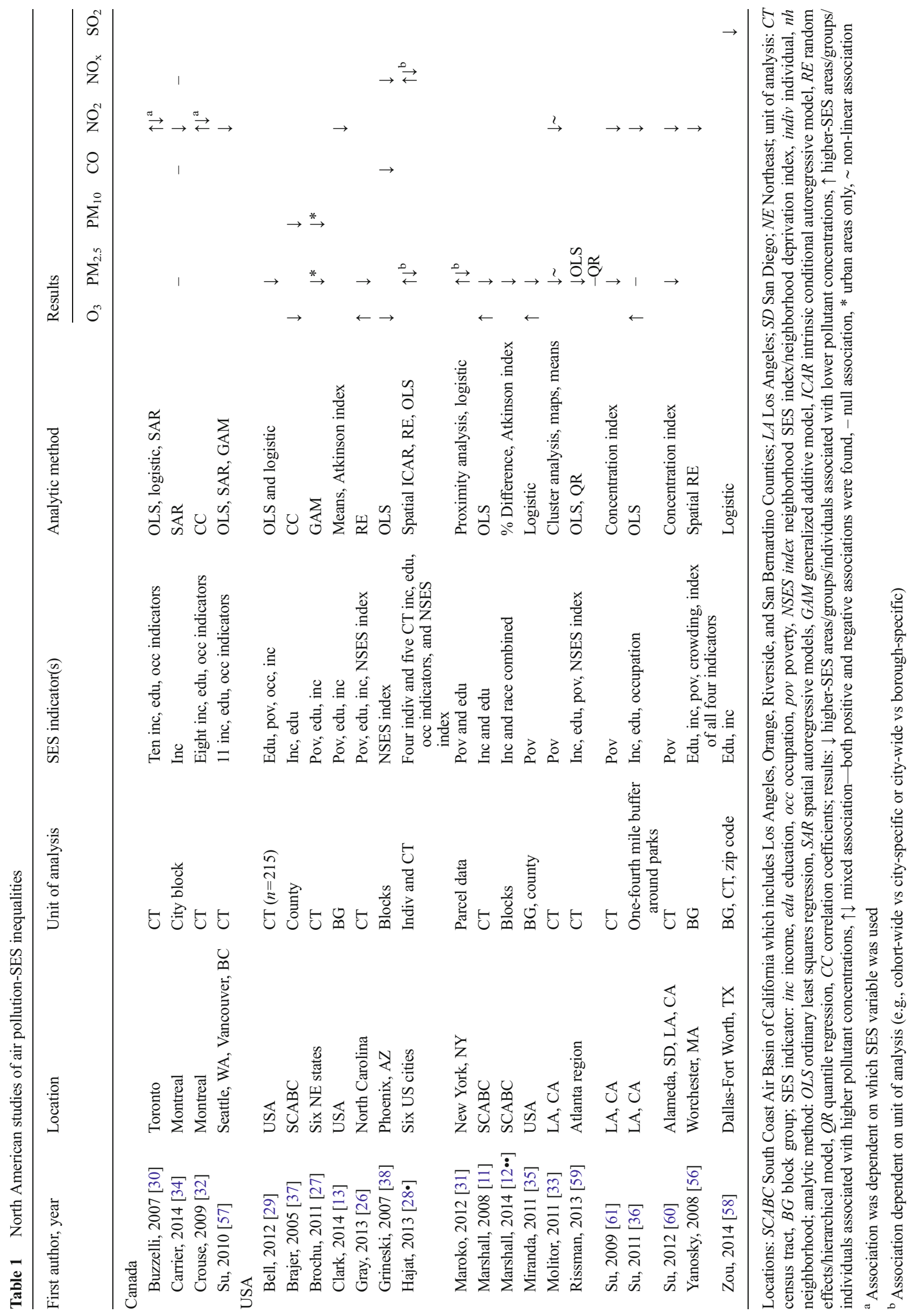


selected census tracts around the USA [29], respectively, with an approximately $15 \%$ greater population of persons with less than a high school education. For context, the EPA $\mathrm{PM}_{2.5}$ standard is $12 \mu \mathrm{g} / \mathrm{m}^{3}$ and the WHO guidelines aim for $25 \mu \mathrm{g} / \mathrm{m}^{3}$.

A few exceptions to this pattern were seen. In New York City (NYC), Toronto, and Montreal, some SES indicators showed the opposite association: higher-SES census tracts had higher concentrations of pollutants [28•, 30-32]. In NYC, a borough-specific analysis revealed that the Bronx and Staten Island had these patterns [31], which is similar to what was found in the Multi-Ethnic Study of Atherosclerosis cohort among study participants who lived in the southern Bronx and northern Manhattan [28 $]$. These results may reflect the fact that these cities developed in such a way that high-SES individuals clustered around busy roadways which often run near rivers and lakes offering more scenic views and better access to urban amenities.

Other North American studies found differences by pollutant. For example, high-poverty clusters in Los Angeles had similar $\mathrm{NO}_{2}$ and $\mathrm{PM}_{2.5}$ concentrations compared to lowpoverty clusters but had higher concentrations of other pollutants [33]. These pollutant-specific results were also seen in a study from Montreal, where higher $\mathrm{NO}_{2}$ concentrations were associated with low-income populations, but no differences across populations were found for $\mathrm{PM}_{2.5}, \mathrm{CO}$, and $\mathrm{NO}_{\mathrm{x}}$ [34]. Several North American studies also found that higher SES groups are exposed to higher concentrations of $\mathrm{O}_{3}$ compared to lower-SES groups $[11,26,35,36]$. This is likely because of the scavenging of $\mathrm{O}_{3}$ by nitric oxide (NO) which can result in lower $\mathrm{O}_{3}$ levels near roadways (where low-income populations are more likely to live) and higher levels further away from them. However, two US studies found $\mathrm{O}_{3}$ levels to be higher among low-SES groups $[37,38]$.

Although research from other parts of the world is limited, studies from New Zealand (NZ), Asia, and Africa also showed negative associations between SES and air pollutants (Table 2). The three studies from NZ found that low-income and high-deprivation neighborhoods had higher concentrations of $\mathrm{PM}_{10}$ compared to higher-SES areas [39-41]. The lone study to address air pollution inequalities in Africa was from Ghana [42•]. That study found that community SES was inversely associated with both $\mathrm{PM}_{2.5}$ and $\mathrm{PM}_{10}$. Lastly, a study from Hong Kong explored a municipality with a strong social safety net which had direct bearing on air pollution inequalities [43•]. The government of Hong Kong provides public housing for low-income residents, while higher-income families obtain housing through the private housing market. Among those living in private housing, the lower-SES population had higher exposure to $\mathrm{PM}_{10}$ compared to the high-SES population. No such inequality was found for residences of public housing. The authors indicate that similar results were found for several other air pollutants. The differential location of public housing facilities appears to be reducing residents' exposure to traffic-related air pollution.

Findings in the European literature were quite mixed (Table 3). Several studies found non-linear patterns of inequality [44-46]. In Strasbourg, France, only the high-SES quintile had lower $\mathrm{NO}_{2}$ concentrations, compared to the other four quintiles that had similar concentrations [45]. Similarly, a European-wide analysis uncovered non-linear trends where middle-income populations had lower $\mathrm{PM}_{10}$ concentrations compared to both higher- and lower-income groups, depending on if analyses focused on Eastern or Western Europe [46]. In London, some high-SES groups had similar $\mathrm{NO}_{\mathrm{x}}$ concentrations to low-SES groups when using a small-area SES metric [44]. Other studies found that the choice of SES metric was relevant to findings, where some SES measures were positively associated with air pollution and others negatively [44, 47, 48]. A pilot study of several cities in the Czech Republic found pollutant-specific results: smaller cities with larger low-SES populations had higher $\mathrm{PM}_{10}$ and $\mathrm{SO}_{2}$ concentrations, while larger cities with larger high-SES populations had higher concentrations of $\mathrm{NO}_{2}$ [49]. Lastly, a Spanish study of pregnant women found no association between individuallevel SES and $\mathrm{NO}_{2}[50]$.

A few European studies from England and Sweden found patterns of inequality similar to those seen in the USA [51-53]. Two UK-based studies found that low-SES groups were exposed to worse air quality $[52,53]$, and a study of a city in Sweden found that low-income children were exposed to higher levels of $\mathrm{NO}_{2}$ compared to children from higherincome families [51]. Patterns similar to those seen in New York and Toronto were also seen in the Netherlands, where low-SES groups were exposed to better air quality compared to high-SES groups [52].

\section{Methodological Issues}

As described above, results from air pollution inequality studies vary depending on place. The methodological approaches used can also result in differences in findings. Previous authors have discussed how some methodological approaches in such studies can yield higher-quality research while avoiding common limitations [1, 54].

The appropriate unit of analysis and the accompanying modifiable areal unit problem (MAUP) in environmental inequality studies have been discussed $[1,17,54,55]$. MAUP refers to the situation where using different units of analysis results in contradictory findings. Several scholars advocate for using smaller levels of geography in order to improve reliability and accuracy of the study $[1,54]$. Very few studies in this review rely exclusively on larger geographic units such as counties [37], cities [49], or regions within a nation [46]. Most of the studies use something similar to or smaller than a US census tract. A few studies use very small geographic 
Table 2 New Zealand, Asian, and African studies of air pollution-SES inequalities

\begin{tabular}{|c|c|c|c|c|c|c|c|}
\hline \multirow[t]{2}{*}{ First author, year } & \multirow[t]{2}{*}{ Location } & \multirow[t]{2}{*}{ Unit of Analysis } & \multirow[t]{2}{*}{ SES indicator(s) } & \multirow[t]{2}{*}{ Analytic method } & \multicolumn{3}{|l|}{ Results } \\
\hline & & & & & $\mathrm{PM}_{2.5}$ & $\mathrm{PM}_{10}$ & $\mathrm{NO}_{\mathrm{x}}$ \\
\hline Fan, $2012[43 \bullet]$ & Hong Kong & Building group & $\begin{array}{l}\text { Education, occupation, } \\
\text { crowding, income, } \\
\text { NSES index }\end{array}$ & Decile, logistic regression & & $\begin{array}{l}\downarrow^{*} \\
{ }^{*} * *\end{array}$ & $\begin{array}{l}\downarrow^{*} \\
{ }^{*} * *\end{array}$ \\
\hline Kingham, 2007 [39] & Christchurch, NZ & Census area unit & Income, NSES index & Means & & $\downarrow$ & \\
\hline Pearce, 2006 [41] & Christchurch, NZ & Census area units & Income, NSES index & Means, OLS & & $\downarrow$ & \\
\hline Pearce, 2008 [40] & Urban areas NZ & Census area unit & Income, NSES index & OLS & & $\downarrow$ & \\
\hline Rooney, 2012 [42•] & Accra, Ghana & Household & NSES index & $\begin{array}{l}\mathrm{RE} \text { accounting for temporal } \\
\text { and spatial autocorrelation }\end{array}$ & $\downarrow$ & $\downarrow$ & \\
\hline
\end{tabular}

Location: NZ New Zealand; SES indicators: NSES index neighborhood SES/deprivation index; analytic method: $O L S$ ordinary least squares regression, $R E$ random effects/hierarchical model; results: $\downarrow$ higher-SES areas/groups associated with lower pollutant concentrations, $\uparrow$ higher-SES areas/groups associated with higher pollutant concentrations, - null association, ${ }^{*}$ private housing only, ${ }^{* *}$ public housing only

areas such as parcel data [31], building of residence [51], or British postcode (mean of 14 households) [44].

Some statistical methods used in environmental inequality research may produce biased findings [1,5]. Although a variety of methods are used to evaluate inequality, many researchers use a regression-based approach to quantify the magnitude and direction of the inequality. In the studies reviewed here, air pollution is the outcome or dependent variable. Ordinary least squares (OLS) regression (i.e., linear regression) assumes that outcomes are independent. Since air pollution often displays a pattern of spatial autocorrelation, it is important to evaluate spatial autocorrelation and use a spatial analytic technique if autocorrelation is present. This will ensure that the independence of observations assumption is not violated.

Many of the studies reviewed do use a spatial regression approach to evaluate the association between SES and air pollution: both spatial generalized additive models (GAM) and spatial autoregressive (SAR) models (i.e., spatial lag or spatial error models) were popular choices. In addition, a few papers used a hierarchical or random effects model that accounted for between neighborhood correlations $[26,44]$ and, in some cases, specified a spatial covariance structure $[42 \bullet, 56]$. A few studies use both spatial and aspatial approaches to underscore differences across models and find that parameter estimates from OLS models tend to overestimate the magnitude of effect compared to spatial approaches (i.e., GAMs or SAR) [28•, 30, 45, 57]. One study compared aspatial multilevel models to a spatial approach and found little difference between the two [28•]. Unfortunately, among studies using regression methods, many do not use methods that account for the clustering of air pollutants across space $[11,26,29,32,35-38,43 \cdot, 44,46,49,50,52$, $58,59]$. Furthermore, these same studies do not report the degree of autocorrelation present in the data, so it is unclear if their choice of model is justified.

Regardless of the use of spatial or aspatial regression approaches for addressing autocorrelation, the issue of adjusting for additional confounders is an important one. It seems plausible that factors such as population density and land use could be important confounders of the air pollution-SES association. However, only a few studies adjust for potential confounders [11, 27, 28• $35,40,42 \bullet, 52]$, leaving parameter estimates subject to bias. The amount of bias will depend on the number and strength of the confounders adjusted for. In the few studies that provide data for both adjusted and unadjusted models, it appears that controlling for several confounders attenuates the parameter estimates [28•,52]. We recognize that confounders may be specific to the study population at hand; thus, future research should explore this issue on a case-by-case basis. Exploring the possibility of potential confounders may result in future environmental inequality studies that provide a less-biased measure of the magnitude of effect.

A related issue pertains to whether air pollution inequality studies pool data (or combine effect estimates) across locations or conduct stratified analyses. A few papers reviewed here provide examples of pooling data within the context of a single study, and all show that pooled analyses tend to mask potentially important patterns found in stratified models [28, 46, 52, 57]. For example, data from an English study show that in the cities of Leeds and London, $\mathrm{PM}_{10}$ and $\mathrm{NO}_{2}$ concentrations increase as SES declines, whereas the association is similar for SES groups in Liverpool and Bristol [52]. These patterns were masked in the country-wide analyses. Understanding the locality-specific patterns will be relevant for policy makers and those considering interventions to reduce the health effects of air pollution.

A few studies have begun using inequality metrics such as the concentration index, Atkinson index, and the slope index of inequality to quantify the inequality present in the data [12••, $13,53,60,61]$. These metrics were first developed by econometricians to assess inequality in income across populations but have since been applied to health and environmental studies [62-64]. Inequality metrics are useful in order to directly compare inequality across groups but may also be useful in assessing high-risk individuals within a population of interest. 


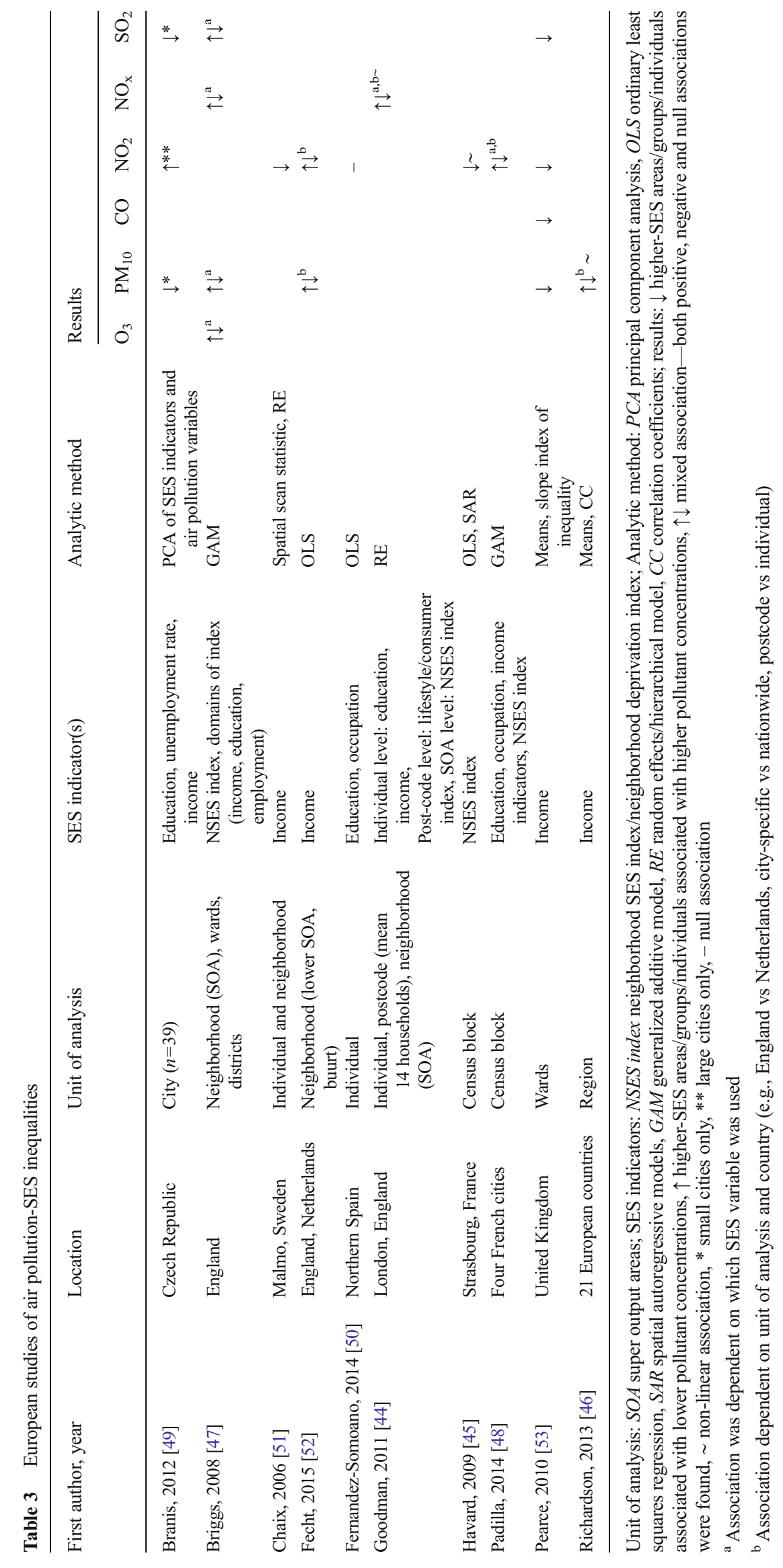


Furthermore, these metrics show much promise in quantifying inequality across time, e.g., before and after a policy is implemented $[10 \bullet \cdot$. The studies using inequality metrics in this review were all cross-sectional in nature. We hope that future studies will apply these metrics to health effects studies to better understand if inequality in the distribution of air pollution is related to environmental health disparities.

Overall, air pollution inequality studies have become more analytically sophisticated over time. Given the important policy ramifications of this work, this is a welcomed development.

\section{Air Pollution Exposure Assessment}

Air pollution exposure assessment has evolved over the past several decades. The move from between-city to within-city estimation has allowed for a reduction in measurement error and the identification of significant variability of air pollution within small geographic areas [65]. The ability to predict air pollution at fine spatial resolution may also be useful for explaining the mixed results seen previously. That is, the ability to incorporate finescale variability in air pollution across space may allow researchers to unmask some of the homogeneity seen in past studies, creating a more nuanced picture of the air pollution-SES association. Furthermore, the advances in exposure assessment may also help us better understand the differing patterns of SES by pollutant, i.e., $\mathrm{O}_{3}$ vs $\mathrm{NO}_{2}$, which have different spatial distributions.

Most of the studies reviewed here used either dispersion models, land use regression (LUR) models, or a hybrid approach which combines a variety of techniques such as LUR and geostatistical interpolation (e.g., kriging) to predict air pollution at unmeasured locations (all except [29, 35, 37, 49]. Very few studies use proximity-based or proximity-weighted approaches [29, 35, 37, 47, 49, 53]. In most cases where these approaches were taken, collecting additional data was not feasible because these studies were interested in providing an assessment of air pollution inequality for the entire nation.

A particularly interesting exposure assessment approach was implemented in Ghana. In light of the lack of government air pollution monitoring in Ghana, the authors undertook an extensive mobile monitoring campaign coupled with the placement of several fixed site monitors and a census of wood and charcoal stoves along the mobile monitoring route. These data were combined to produce detailed exposure maps which showed significant spatial variability both within and between the neighborhoods under study $[42 \bullet, 66]$. Such extensive efforts may be required to characterize inequality in less-industrialized nations where routine ambient air quality monitoring is lacking.

Some studies looked at specific sources of air pollution (e.g., road versus industrial) $[11,33,58]$ or components of a more complex mixture [29]. Source-specific studies may guide regulations and other interventions which may have a more direct impact on reducing air pollution inequalities.

\section{SES Measures}

SES is a complex construct that has been operationalized with a variety of different measures, including income, education, and occupation [67]. SES measures take different forms in less-industrialized countries where housing type, water and electricity access, and assets in the form of cattle and televisions are often used [68]. In terms of area-level measures of SES, the British have led the way in articulating the need for a deprivation index, an index composed of several individual metrics to measure a relative lack of resources along several dimensions (social, material) [69].

Many authors agree that using only one indicator of SES (e.g., income) may not sufficiently capture the broader construct of SES. For example, some US health studies ask one question on income or education and assume that item sufficiently measures (with minimal measurement error) this relatively complex construct. However, it is also widely acknowledged that indicators of SES tend to be highly correlated, and thus, using multiple measures within a single model is not recommended. SES indices based on principal components analysis or a similar dimension reduction technique are intended to address this issue. Fourteen studies in this review use some sort of SES index [26, 28• , 38-41, 42• 43•, 44, 45, $47,48,56,59]$. As a part of the nationwide multidomain deprivation index, a few studies from the UK used several indicators such as number of families receiving income support or some other means-tested benefit offered by the government to better capture the concept of income deprivation [70]. To date, only air pollution inequality studies from Canada have not embraced the use of an SES index.

Another important methodological issue with implications for health effects studies is the use of both individual- and area-level SES metrics. To better understand the role of SES as a confounder of the air pollution-health association, data at both individual and area levels are needed. Only a few studies have included both levels of data [28•,44,51], and all have found stronger associations with air pollution for area/ neighborhood-level SES compared to individual-level SES. Because of the relatively limited knowledge based on how both levels may singly and/or jointly influence air pollution exposures and associated health outcomes and because preventive interventions often differ by level, future studies should evaluate the role of both individual- and area-level SES metrics in their specific populations.

\section{Conclusions}

Much, but not all, of the environmental inequality literature from North America, NZ, Asia, and Africa, to date, has shown that low-SES communities face higher concentrations of criteria air pollutants. The European research, on the other 
hand, is quite mixed. Some studies found that SES was positively associated with air pollution, while others found a negative association, and still, others found patterns suggesting similar levels regardless of social class. These results suggest the need for further, more rigorous examination of the air pollution-SES association in Europe. Overall, there is a paucity of environmental inequality research from nations outside the USA, but the concepts of EJ and inequality are taking hold around the world, and we anticipate more research in years to come. In particular, rapidly developing nations like India and China are understudied assessing if economic development distributes air pollution unequally across these population may have sizeable impacts for population health.

Although several methodological advances in this body of research have occurred, future researchers may want to consider some methodological areas of particular importance. First, understanding the spatial structure of the air pollution data is a critical first step in choosing an analytic approach. Secondly, researchers may want to explore the possibility of confounders of the air pollution-SES association. Methodological improvements in both these areas will provide more accurate point estimates and standard errors.

Environmental inequality research has implications for health effects analyses. First, it is important for health researchers to know if individual- and/or area-level SES confounds the air pollution-health outcome association. SES, like air pollution, can be highly variable from place to place, and researchers should carefully consider what it represents in the context of health studies. Environmental inequality studies can provide an in-depth look at one piece of the confounding triangle, but only if both individual- and area-level SESs are explored. Few studies, to date, have tackled this question $[28 \cdot, 44,51]$.

More importantly, the question of whether differential exposure to air pollution is driving environmental health disparities is relevant from a regulatory and public health perspective. In the USA, evidence supports that many (but not all) low-SES communities bear a disproportionate burden of air pollution. For these communities, it is plausible that differential exposure to air pollution may be a contributor to higher associations between air pollution and health than seen in better-off populations. In some European studies, however, higher air pollution concentrations were found among higher-SES populations, but the health effects of air pollution were still distributed disproportionately among the poor [71-74]. The observation that communities where high-SES groups live have higher concentrations of air pollution does not necessarily mean that the residents are more exposed. High-SES individuals have access to more resources that can protect them from increased exposure, such as private transportation versus public, indoor versus outdoor work environments, better constructed housing and, potentially, access to climate control, including filtration, for indoor environments $[71,75]$. Alternatively, environmental health disparities in Europe could be driven by other environmental hazards, such as noise, second-hand smoke, or other work- or housing-related indicators, many of which are also linked to the social environment and disproportionately impact the poor [19]. Additional research into the social distribution of air pollution in Europe will require a rigorous, areaspecific approach to shed light on what is likely to be a quite nuanced reality.

Understanding how environmental inequality is created may help explain air pollution and inequality research and has implications for policy. It has been hypothesized that low-SES communities with limited political power and influence are unable to stop locally undesirably land uses (LULU), such as factories and roads, from being built in their communities. That is, poor communities lack social capital, a necessary prerequisite for mounting an effective campaign against placing a LULU in one's community. On the other hand, it has been suggested that industry is motivated solely by economic factors: building a LULU on cheap land is economically prudent. The presence of a LULU will then result in the decline in property values which makes an area more accessible for low-SES and minority populations [6, 76]. Both of these theories point to the importance of class- and race-based residential segregation in creating inequality in air pollution concentrations across space. It should be noted that much of the research about causes of environmental inequalities has focused on the US context. Given the importance of historical, economic, and social contexts in understanding inequality, other nations may have very different explanations for why environmental inequalities exist.

One strength of the environmental inequality literature as reviewed here is its truly interdisciplinary nature. Researchers from a diverse set of fields bring their own tools and lenses to the question of inequality, making this body of research primed for innovation. In the studies reviewed here, authors were from a wide array of disciplines including the following: geography, sociology, economics, epidemiology, urban studies, environmental health sciences, environmental studies, and civil engineering.

Several open research areas and knowledge gaps exist. First, very few studies have examined changes in inequality over time $[37,48]$. Since levels of air pollution have declined over time, particularly in North America, it is of interest to understand if the unequal distribution of air pollution is widening or narrowing. Specifically, as air pollution policies and regulations (both related and unrelated to inequality) are put into place, it is important to understand if these policies impact inequality. Another policy-relevant issue is that of which sources or components are most unequally distributed. Although a few studies have begun to examine this question, inequalities may be driven by local sources of pollution, thus necessitating more research. Finally, although this review did not specifically address race/ethnicity, understanding how these factors relate to socioeconomic factors in terms of location-based variability in air pollution concentrations is important for EJ. 
Research that pursues these and other questions that directly inform policy changes to enhance environmental quality and health equity is essential in continuing global efforts to improve health and provide safe environments for all.

\section{Compliance with Ethics Guidelines}

Conflict of Interest Anjum Hajat, Charlene Hsia, and Marie S. O'Neill declare that they have no conflict of interest.

Human and Animal Rights and Informed Consent Ethical approval: All procedures performed in studies involving human participants were in accordance with the ethical standards of the institutional and/or national research committee and with the 1964 Helsinki declaration and its later amendments or comparable ethical standards.

\section{References}

Papers of particular interest, published recently, have been highlighted as:

- Of importance

•- Of major importance

1. Bowen W. An analytical review of environmental justice research: what do we really know? Environ Manag. 2002;29:3-15.

2. Brown P. Race, class, and environmental health: a review and systematization of the literature. Environ Res. 1995;69:15-30.

3. Brulle RJ, Pellow DN. Environmental justice: human health and environmental inequalities. Annu Rev Public Health. 2006;27:103-24.

4. Evans GW, Kantrowitz E. Socioeconomic status and health: the potential role of environmental risk exposure. Annu Rev Public Health. 2002;23:303-31.

5. Miao Q, Chen DM, Buzzelli M, et al. Environmental equity research: review with focus on outdoor air pollution research methods and analytic tools. Arch Environ Occup Health. 2015;70:47-55.

6. Mohai P, Pellow D, Roberts JT. Environmental justice. Annu Rev Environ Resour. 2009;34:405-30.

7. Pulido L. A critical review of the methodology of environmental racism research. Antipode. 1996;28:142-59.

8. Szasz A, Meuser M. Environmental inequalities: literature review and proposals for new directions in research and theory. Curr Sociol. 1997;45:99-120.

9. Ringquist EJ. Assessing evidence of environmental inequities: a meta-analysis. J Policy Anal Manage. 2005;24:223-47.

$10 . \bullet$ Harper S, Ruder E, Roman HA, et al. Using inequality measures to incorporate environmental justice into regulatory analyses. Int $\mathrm{J}$ Environ Res Public Health. 2013;10:4039-59. This is a good review of the various inequality metrics that can be applied to environmental inequality studies.

11. Marshall JD. Environmental inequality: air pollution exposures in California's South Coast Air Basin. Atmos Environ. 2008;42: 5499-503.

12.• Marshall JD, Swor KR, Nguyen NP. Prioritizing environmental justice and equality: diesel emissions in Southern California. Environ Sci Technol. 2014;48:4063-8. This paper measures both inequality and injustice in addition to the impact of the pollutant. Furthermore, it looks at source-specific air pollution which as noted above has policy and regulatory impact
13. Clark LP, Millet DB, Marshall JD. National patterns in environmental injustice and inequality: outdoor $\mathrm{NO}_{2}$ air pollution in the United States. Plos One. 2014;9:8.

14. Laurent O, Bard D, Filleul L, et al. Effect of socioeconomic status on the relationship between atmospheric pollution and mortality. $\mathrm{J}$ Epidemiol Community Health. 2007;61:665-75.

15. Institute of Medicine Committee on Environmental Justice. Toward environmental justice: research, education, and health policy needs. National Academies Press (US); 1999.

16. Morello-Frosch R, Shenassa ED. The environmental "riskscape" and social inequality: implications for explaining maternal and child health disparities. Environ Health Perspect. 2006;114:1150-3.

17. O'Neill MS, Jerrett M, Kawachi L, et al. Health, wealth, and air pollution: advancing theory and methods. Environ Health Perspect. 2003;111:1861-70.

18. Kaufman JS, Cooper RS. Commentary: considerations for use of racial/ethnic classification in etiologic research. Am J Epidemiol. 2001;154:291-8.

19. World Health Organization. Environmental health inequalities in Europe: assessment report. 2012.

20. US Environmental Protection Agency. National Ambient Air Quality Standards (NAAQS). 2014. http://www.epa.gov/air/ criteria.html. Accessed 31 July 2015.

21. European Commission. Air Quality Standards. 2015. http://ec. europa.eu/environment/air/quality/standards.htm. Accessed 31 July 2015.

22. Backes $\mathrm{CH}$, Nelin T, Gorr MW, et al. Early life exposure to air pollution: how bad is it? Toxicol Lett. 2013;216:47-53.

23. Bascom R, Bromberg PA, Costa DA, et al. Health effects of outdoor air pollution. Committee of the Environmental and Occupational Health Assembly of the American Thoracic Society. Am J Respir Crit Care Med. 1996;153:3-50.

24. Block ML, Elder A, Auten RL, et al. The outdoor air pollution and brain health workshop. Neurotoxicology. 2012;33:972-84.

25. Brook RD, Rajagopalan S, Pope 3rd CA, et al. Particulate matter air pollution and cardiovascular disease: an update to the scientific statement from the American Heart Association. Circulation. 2010;121:2331-78

26. Gray SC, Edwards SE, Miranda ML. Race, socioeconomic status, and air pollution exposure in North Carolina. Environ Res. 2013;126:152-8.

27. Brochu PJ, Yanosky JD, Paciorek CJ, et al. Particulate air pollution and socioeconomic position in rural and urban areas of the northeastern United States. Am J Public Health. 2011;101:S224-30.

28. Hajat A, Diez-Roux AV, Adar SD, et al. Air pollution and individual and neighborhood socioeconomic status: evidence from the MultiEthnic Study of Atherosclerosis (MESA). Environ Health Perspect. 2013;121:1325-33. This is one of the few papers that evaluates both individual and neighborhood SES, using individual-level air pollution data, thus making it one of the few studies that does not have an ecological study design.

29. Bell ML, Ebisu K. Environmental inequality in exposures to airborne particulate matter components in the United States. Environ Health Perspect. 2012;120:1746-52.

30. Buzzelli M, Jerrett M. Geographies of susceptibility and exposure in the city: environmental inequity of traffic-related air pollution in Toronto. Can J Reg Sci. 2007;30:195-210.

31. Maroko AR. Using air dispersion modeling and proximity analysis to assess chronic exposure to fine particulate matter and environmental justice in New York City. Appl Geogr. 2012;34:533-47.

32. Crouse DL, Ross NA, Goldberg MS. Double burden of deprivation and high concentrations of ambient air pollution at the neighbourhood scale in Montreal, Canada. Soc Sci Med. 2009;69: 971-81.

33. Molitor J, Su J, Molitor NT, et al. Identifying vulnerable populations through an examination of the association between multi- 
pollutant profiles and poverty. Environ Sci Technol. 2011;45:775460 .

34. Carrier M, Apparicio P, Seguin AM, et al. The application of three methods to measure the statistical association between different social groups and the concentration of air pollutants in Montreal: a case of environmental equity. Transp Res Part D Transp Environ. 2014;30:38-52.

35. Miranda ML, Edwards SE, Keating MH, et al. Making the environmental justice grade: the relative burden of air pollution exposure in the United States. Int J Environ Res Public Health. 2011;8:1755-71.

36. $\mathrm{Su} \mathrm{JG}$, Jerrett M, de Nazelle A, et al. Does exposure to air pollution in urban parks have socioeconomic, racial or ethnic gradients? Environ Res. 2011;111:319-28.

37. Brajer V, Hall JV. Changes in the distribution of air pollution exposure in the Los Angeles basin from 1990 to 1999. Contemp Econ Policy. 2005;23:50-8.

38. Grineski S, Bolin B, Boone C. Criteria air pollution and marginalized populations: environmental inequity in metropolitan Phoenix, Arizona. Soc Sci Q. 2007;88:535-54.

39. Kingham S, Pearce J, Zawar-Reza P. Driven to injustice? Environmental justice and vehicle pollution in Christchurch, New Zealand. Transp Res Part D Transp Environ. 2007;12:254-63.

40. Pearce J, Kingham S. Environmental inequalities in New Zealand: a national study of air pollution and environmental justice. Geoforum. 2008;39:980-93.

41. Pearce J, Kingham S, Zawar-Reza P. Every breath you take? Environmental justice and air pollution in Christchurch, New Zealand. Environ Plan A. 2006;38:919-38.

42. Rooney MS, Arku RE, Dionisio KL, et al. Spatial and temporal patterns of particulate matter sources and pollution in four communities in Accra, Ghana. Sci Total Environ. 2012;435:107-14. This is the first study from Africa to evaluate SES inequalities, albeit briefly, in criteria air pollution concentrations. The exposure assessment uses a mobile monitoring platform to compensate for the lack of government air pollution data.

43. Fan XP, Lam KC, Yu Q. Differential exposure of the urban population to vehicular air pollution in Hong Kong. Sci Total Environ. 2012;426:211-9. This is one of the few papers to highlight inequality in the distribution of criteria air pollutants in an Asian setting. This paper suggests that both residential mobility and market forces may influence air pollution exposure and shows how government housing policy can influence air pollution exposure.

44. Goodman A, Wilkinson P, Stafford M, et al. Characterising socioeconomic inequalities in exposure to air pollution: a comparison of socio-economic markers and scales of measurement. Health Place. 2011;17:767-74.

45. Havard S, Deguen S, Zmirou-Navier D, et al. Traffic-related air pollution and socioeconomic status: a spatial autocorrelation study to assess environmental equity on a small-area scale. Epidemiology. 2009;20:223-30.

46. Richardson EA, Pearce J, Tunstall H, et al. Particulate air pollution and health inequalities: a Europe-wide ecological analysis. Int $\mathrm{J}$ Health Geogr. 2013;12:34.

47. Briggs D, Abellan JJ, Fecht D. Environmental inequity in England: small area associations between socio-economic status and environmental pollution. Soc Sci Med. 2008;67:1612-29.

48. Padilla CM, Kihal-Talantikite W, Vieira VM, et al. Air quality and social deprivation in four French metropolitan areas - a localized spatio-temporal environmental inequality analysis. Environ Res. 2014;134:315-24.

49. Branis M, Linhartova M. Association between unemployment, income, education level, population size and air pollution in Czech cities: evidence for environmental inequality? A pilot national scale analysis. Health Place. 2012;18:1110-4.
50. Fernandez-Somoano A, Tardon A. Socioeconomic status and exposure to outdoor $\mathrm{NO}_{2}$ and benzene in the Asturias INMA birth cohort, Spain. J Epidemiol Community Health. 2014;68:29-36.

51. Chaix B, Gustafsson S, Jerrett M, et al. Children's exposure to nitrogen dioxide in Sweden: investigating environmental injustice in an egalitarian country. J Epidemiol Community Health. 2006;60: 234-41.

52. Fecht D, Fischer P, Fortunato L, et al. Associations between air pollution and socioeconomic characteristics, ethnicity and age profile of neighbourhoods in England and the Netherlands. Environ Pollut. 2015;198:201-10.

53. Pearce JR, Richardson EA, Mitchell RJ, et al. Environmental justice and health: the implications of the socio-spatial distribution of multiple environmental deprivation for health inequalities in the United Kingdom. Trans Inst Br Geogr. 2010;35:522-39.

54. Maantay J. Mapping environmental injustices: pitfalls and potential of geographic information systems in assessing environmental health and equity. Environ Health Perspect. 2002;110:161-71.

55. Soobader M, Cubbin C, Gee GC, et al. Levels of analysis for the study of environmental health disparities. Environ Res. 2006;102: 172-80.

56. Yanosky JD, Schwartz J, Suh HH. Associations between measures of socioeconomic position and chronic nitrogen dioxide exposure in Worcester, Massachusetts. J Toxic Environ Health A. 2008;71: 1593-602.

57. Su JG, Larson T, Gould T, et al. Transboundary air pollution and environmental justice: Vancouver and Seattle compared. GeoJournal. 2010;75:595-608

58. Zou B, Peng F, Wan N, et al. Sulfur dioxide exposure and environmental justice: a multi-scale and source-specific perspective. Atmos Pollut Res. 2014;5:491-9.

59. Rissman J, Arunachalam S, BenDor T, et al. Equity and health impacts of aircraft emissions at the Hartsfield-Jackson Atlanta International Airport. Landsc Urban Plan. 2013;120:234-47.

60. Su JG, Jerrett M, Morello-Frosch R, et al. Inequalities in cumulative environmental burdens among three urbanized counties in California. Environ Int. 2012;40:79-87.

61. Su JG, Morello-Frosch R, Jesdale BM, et al. An index for assessing demographic inequalities in cumulative environmental hazards with application to Los Angeles, California. Environ Sci Technol. 2009;43:7626-34.

62. Barr LM, Pressey RL, Fuller RA, et al. A new way to measure the world's protected area coverage. Plos One. 2011;6:4.

63. Fann N, Roman HA, Fulcher CM, et al. Maximizing health benefits and minimizing inequality: incorporating local-scale data in the design and evaluation of air quality policies. Risk Anal. 2011;31: 908-22.

64. Harper S, Lynch J, Meersman SC, et al. An overview of methods for monitoring social disparities in cancer with an example using trends in lung cancer incidence by area-socioeconomic position and race-ethnicity, 1992-2004. Am J Epidemiol. 2008;167:889-99.

65. Brauer M, Hoek G, van Vliet $\mathrm{P}$, et al. Estimating long-term average particulate air pollution concentrations: application of traffic indicators and geographic information systems. Epidemiology. 2003;14:228-39.

66. Dionisio KL, Arku RE, Hughes AF, et al. Air pollution in Accra neighborhoods: spatial, socioeconomic, and temporal patterns. Environ Sci Technol. 2010;44:2270-6.

67. Oakes JM, Rossi PH. The measurement of SES in health research: current practice and steps toward a new approach. Soc Sci Med. 2003;56:769-84.

68. Fotso J-C, Kuate-Defo B. Measuring socioeconomic status in health research in developing countries: should we be focusing on households, communities or both? Soc Indic Res. 2005;72:189-237.

69. Townsend P. Deprivation. J Soc Policy. 1987;16:125-46. 
70. McLennan D, Barnes H, Noble M, et al. The English indices of deprivation 2010. London: Department for Communities and Local Government; 2011.

71. Cesaroni G, Badaloni C, Romano V, et al. Socioeconomic position and health status of people who live near busy roads: the Rome Longitudinal Study (RoLS). Environ Health. 2010;9.

72. Dragano N, Hoffmann B, Moebus S, et al. Traffic exposure and subclinical cardiovascular disease: is the association modified by socioeconomic characteristics of individuals and neighbourhoods? Results from a multilevel study in an urban region. Occup Environ Med. 2009;66:628-35.
73. Forastiere F, Stafoggia M, Tasco C, et al. Socioeconomic status, particulate air pollution, and daily mortality: differential exposure or differential susceptibility. Am J Ind Med. 2007;50:208-16.

74. Næss Ø, Piro FN, Nafstad P, et al. Air pollution, social deprivation, and mortality: a multilevel cohort study. Epidemiology. 2007;18:686-94.

75. Spalt EW, Curl CL, Allen RW, et al. Factors influencing timelocation patterns and their impact on estimates of exposure: the Multi-Ethnic Study of Atherosclerosis and Air Pollution (MESA Air). J Expo Sci Environ Epidemiol. 2015.

76. Saha R, Mohai P. Historical context and hazardous waste facility siting: understanding temporal patterns in Michigan. Soc Probl. 2005;52:618-48. 